\title{
Development and Evaluation of Polyherbal Lozenges for Cold and Flu
}

\author{
Anshul Kumar', Manish Kumar Mishra', Afeefa ${ }^{1}$, Chandrashekar K.S ${ }^{1}$, Girish Pai ${ }^{2}$, Vasudev Pai ${ }^{1, \star}$ \\ ${ }^{1}$ Department of Pharmacognosy, Manipal College of Pharmaceutical Sciences, Manipal Academy of Higher Education, Manipal, \\ Karnataka, INDIA. \\ ${ }^{2}$ Department of Pharmaceutics, Manipal College of Pharmaceutical Sciences, Manipal Academy of Higher Education, Manipal, \\ Karnataka, INDIA.
}

\begin{abstract}
Background: Lozenges are solid dosage form which are intended to slowly dissolve in the mouth for therapeutic effect. Common cold and flu are common diseases which usually infects the respiratory tract including symptoms like head and body ache, fever, drowsiness, runny nose, congestion and cough. Aim: The present polyherbal lozenge formulations developed to eliminate all symptoms of cold and flu. Although many herbal and allopathic drugs are available, but they are not sufficient to treat all the symptoms through one formulation. Materials and Methods: Jaggery and sugar were dissolved in water and all the juices of drugs mixed and heated till suitable consistency and finally poured in lozenges mold and cooled to form lozenges. Results: The lozenges are evaluated for various quality parameters like hardness, friability, thickness, weight uniformity and disintegration time which comply with the standard mentioned in GMP guidelines. Conclusion: Lozenge is completely herbal containing no synthetic ingredient and is economical to treat all the symptoms of cold and flu.
\end{abstract}

Key words: Polyherbal lozenges, Common col, Flu Polyherbal, Lozenges, Formulations, Cold, Flu, Standardization.

\section{INTRODUCTION}

The lozenges are the medicated tablet kept in the mouth until it gets dissolved and releases the medicament and produces the soothing effect on throat. Varieties of lozenges are usually used to treat cough and sore throat. Lozenges are dissolved slowly in the mouth to stop the cough and soothe irritation of the tissues in the throat. ${ }^{1,2}$

\section{History of Lozenges}

Candies were used to soothe the throat since date back to 1000 BC in Egypt's Twentieth Dynasty, when the candies were made from pure honey and flavored with juices of citrus fruits, various herbs and some valuable spices. In the $19^{\text {th }}$ century, some of the physicians used morphine and heroin from opium, which has antitussive property. Most popular formulations at that era were by Smith Brothers Cough Drops and was first advertised in the year 1850 and Luden's, created in 1880. Later the concern over the risk of opioid dependence and addition which led to the development of alternative medications. $^{3-5}$

\section{About the Disease}

Influenza is popularly known as "the flu", which is a infectious disease caused by an influenza virus. Symptoms are be mild to severe. The common symptoms are: a high fever, loose runny nose, sore throat, pain in the muscle, irritating headache, frequent coughing and tiredness.

\section{About Herbal Drugs}

An herb is a plant or plant part used for its therapeutic properties, flavor or scent. Herbal drugs are type of dietary supplements, hence they are marketed as differ-
Submission Date: 29-11-2018; Revision Date: 12-12-2018; Accepted Date: 20-03-2019.

DOI: 10.5530/ijper.53.2s.61 Correspondence: Mr. Vasudev Pai, Department of Pharmacognosy, Manipal College of

Pharmaceutical Sciences, Manipal Academy of Higher Education, Manipal, Karnataka- 576104, INDIA.

Phone: +91-0820-2922482

E-mail: pai.vasudev@

manipal.edu

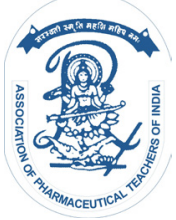

www.ijper.org 
ent dosage forms like tablets, capsules, powders, in the form of tea bags, solid extracts and sometimes as fresh or dried plants. People use herbal drugs to maintain or improve their general health.

\section{About the Ingredients}

\section{Liquorice}

It is the root of Glycyrrbiza glabra (Family: Leguminosae) from which a sweet flavour can be extracted. The liquorice plant is a herbaceous perennial legume native to southern Europe and parts of Asia, such as India. It is also known as mulethi and Jestamadhu in India and is widely used in Ayurvedic system of medicine for various ailment related to respiratory system. Used as Expectorant and Demulcent. These properties are due to the presence of Glycyrrhenic acid.

\section{Clove}

Cloves are the aromatic flower buds of a tree (Myrtaceae) Sysygium aromaticum (Eugenia caryophyllus). They are native to the Maluku Islands (or Moluccas) in Indonesia. Used as an analgesic and antiviral. These effects are because of the presence of Eugenol and other constituents in the flower bud.

\section{Ginger}

It consists of rhizomes of Zinziber officinale (Fam.: Zinziberaceae), scrapped to remove the dark outer skin and dried in the sun. Ginger mainly contain oleo-resin which has aromatic, carminative and expectorant property. Gingerol is the active principle of fresh ginger, it is normally found as a yellow pungent oil and has spicy-sweet aroma.

\section{Long Pepper}

It consists of the dried unripe or nearly ripe fruits of perennial climbing vine $s$ (Family: Piperaceae). It is also called as long native pepper and pipli in Hindi. In Ayurveda long pepper is widely used for various formulations because of its wide range of therapeutic applications. It has a taste same to, but hotter than other closely related species of pepper. Pepper in mainly indicated in respiratory disorders in cold, as decongestant, helps in expelling out mucus accumulated in the respiratory tract, bronchodilator in asthma patients, also in fever.

\section{Honey}

It is a saccharine fluid (From the nectar of flower) deposited in the honey comb by the hive bee, Apismallifera, Apisdorsata and other species of Apis (Fam: Apidae). Honey is well known home remedy for dry cough as well as wet cough because of its consistence. It is having soothing effect helps in relieving irritation in the throat.

\section{Guduchi}

Guduchi consists of dried, matured pieces of stem of Tinospora cordifolia (Family-Menispermaceae). It is also known as Giloy which very popular herb in Ayurveda is extensively used in fever and respiratory problems, diabetes, anemia, cardiac disorders etc.

\section{Vasaka}

It consists of the fresh and dried leaves of Adhatoda vasica (Family: Acanthaceae). Vasaka is an important Ayurvedic medicinal herb. The entire parts of the plant from roots to leaves are used to treat many diseases. Leaves of the plant have great importance in the treatment of asthama, bronchitis, tuberculosis and other it is very good mucolytic. Vasaka contains vasicine which has mucolytic property used in various herbal expectorant formulations.

\section{Turmeric}

They are dried rhizomes of Curcuma longa (Zingiberaceae). Turmeric is one of the spice widely used in Indian dishes because of its yellow colour. It possesses antiseptic property hence used for respiratory conditions like common cold, bronchitis, cough and other upper respiratory problems. It is also protective to skin and hence used in cosmetic products. It contains curcuminoids and curcumin is chief constituents which has many therapeutic applications.

The various ingredients used for formulation is given in Figure 1.

\section{MATERIALS AND METHODS}

\section{Method of Preparation of Lozenges}

Jaggery and sugar were dissolved in little water till a sufficient consistency was obtained. In another container little water was added and all the herbs were added and mixed thoroughly and finally filtered. Sugar and jaggery syrup was poured in the beaker containing the filtered herbal juice. Honey was added. The mixture was heated with constant stirring until it reached a temperature of $150^{\circ} \mathrm{C}$. The preparation was then removed from heat and was poured on a lozenge mold to get lozenges of ideal size. The mold was allowed to cool and harden at room temperature. After cooling the hard lozenges were tossed over powdered sugar to avoid getting sticky in humidity. The sugar powder tossed lozenges are stored in a wide mouthed air tight container in a cool place.

Herbs used for formulation-1 are Liquorice, Clove, Ginger, Long pepper, Guduchi and Turmeric and formula- 
tion-2 includes Liquorice, Clove, Ginger, Long pepper, Guduchi and Vasaka. Honey was used for both the formulation to produce soothing effect on throat.

\section{Survey}

A survey was done on 100 volunteers through a questionnaire to check acceptability of different parameters and quality of the lozenge. A scoring was done where 1 was the highest and 5 was the least. The pattern of questionnaire is given in Figure 2.

\section{Physico-Chemical Parameters}

The prepared lozenges were evaluated for its organoleptic parameters like colour, odour, taste and touch, hardness, weight uniformity etc.

The Hardness testing was done by using PFIZER hardness tester of $(n=5)$ and the average was taken. Thickness $(n=5)$ of lozenges were calculated using thickness apparatus, friability test is done by friability test apparatus $(n=5)$. Weigh uniformity was determined by weighing 5 lozenges individually, the average weigh was calculated and the percent variation of each tablet was determined. ${ }^{6,7}$

\section{Disintegration Time Studies}

Disintegration time is the interval required for complete disappearance of a lozenges or its particles from the tester net. Disintegration test of the prepared lozenges was performed according to USP30, using a disintegration tester through the disintegration medium of phosphate buffer with $\mathrm{pH} 6.2$ maintained at $37 \pm 0.5^{\circ} \mathrm{C}$.
Economic Survey: Average cost for the lozenge was asked from the volunteers they would pay through questionnaire. ${ }^{8-10}$

\section{Organoleptic characters}

A survey was done on 100 volunteers to know the organoleptic acceptability through a questionnaire.

\section{Measurement of $\mathrm{pH}$}

The acidity or alkalinity of a lozenges was indicated by using lab $\mathrm{pH}$ meter, a scale from 1.0 to $14.0 .1 \% \mathrm{~W} / \mathrm{V}$ solution of candy was prepared by dissolving $1 \mathrm{~g}$ candy in $100 \mathrm{ml}$ distilled water and its $\mathrm{pH}$ was recorded.

\section{RESULTS AND DISCUSSION}

The hardness $(n=5)$, friability $(n=5)$, thickness $(n=5)$, weight uniformity $(n=5)$ and disintegration time $(n=5)$ of prepared lozenges were evaluated and results are given in Table 1 and Table 2.

\section{pH of candy}

The $p \mathrm{H}$ of $1 \% \mathrm{w} / \mathrm{v}$ solution of herbal lozenges in distilled water was found to be 4.5 for formulation 1 and 4.7 for formulation 2 .

The lozenge were administered to 100 patients with cold and flu and the feedback was taken with the help of a questionnaire. The results are shown in the Table 3 below with average scores.

Scoring Key: 5 is the highest and 1 is the least.

The acceptance criteria of any lozenges from market was analyzed in the form of questionnaire feedback

\begin{tabular}{|c|c|c|c|c|c|}
\hline \multicolumn{7}{|c|}{ Table 1: Evaluation of Formulation - 1. } \\
\hline SL. No & $\begin{array}{c}\text { Hardness } \\
\text { Kg/cm }\end{array}$ & Friability (\%) & $\begin{array}{c}\text { Thickness } \\
(\mathbf{m m})\end{array}$ & $\begin{array}{c}\text { Weight uniformity } \\
(\mathbf{m g})\end{array}$ & $\begin{array}{c}\text { Disintegration time } \\
\text { (Min) }\end{array}$ \\
\hline 1. & 18.07 & 0.50 & 12.34 & 728.65 & 8.10 \\
\hline 2. & 16.46 & 0.58 & 11.87 & 758.90 & 8.90 \\
\hline 3. & 18.12 & 0.70 & 12.57 & 796.84 & 7.90 \\
\hline 4. & 17.43 & 0.58 & 10.76 & 804.98 & 8.30 \\
\hline 5. & 18.99 & 0.74 & 11.76 & 783.87 & 9.79 \\
\hline
\end{tabular}

\begin{tabular}{|c|c|c|c|c|c|}
\hline \multicolumn{7}{|c|}{ Table 2: Evaluation of Formulation - 2. } \\
\hline SL. No & $\begin{array}{c}\text { Hardness } \\
\text { Kg/cm }\end{array}$ & Friability (\%) & $\begin{array}{c}\text { Thickness } \\
\text { (mm) }\end{array}$ & $\begin{array}{c}\text { Weight uniformity } \\
\text { (mg) }\end{array}$ & $\begin{array}{c}\text { Disintegration time } \\
\text { (Min) }\end{array}$ \\
\hline 1. & 17.89 & 0.78 & 11.64 & 738.05 & 8.50 \\
\hline 2. & 16.96 & 0.68 & 10.37 & 748.60 & 8.30 \\
\hline 3. & 16.32 & 0.50 & 12.87 & 766.34 & 7.40 \\
\hline 4. & 15.63 & 0.68 & 11.76 & 704.78 & 7.50 \\
\hline 5. & 18.09 & 0.54 & 13.06 & 743.67 & 9.39 \\
\hline
\end{tabular}




\begin{tabular}{|c|c|}
\hline Table 3: Feedback Questionnaire Average Score. \\
\hline PARAMETERS & $\begin{array}{c}\text { AVERAGE } \\
\text { SCORE }\end{array}$ \\
\hline Colour Acceptability & 3 \\
\hline Taste and Palatability & 4 \\
\hline Ease of Dissolution & 5 \\
\hline Safety and Sterility & 4 \\
\hline Duration of action and Satisfaction & 4 \\
\hline Recommendation to other flu patients & 4 \\
\hline $\begin{array}{c}\text { Comparison with other marketed } \\
\text { lozenges }\end{array}$ & 3 \\
\hline
\end{tabular}

of 100 volunteers. The results are given in Figure 3 as acceptance parameter scoring

Factors affecting the choice of selection of any lozenges from market.

\section{Economic Survey}

Average price for one Lozenge, volunteers (100) willing to pay: Rs 3.

\section{CONCLUSION}

Polyherbal lozenges have been developed with 6 different herbs. The various measures taken for the qualitative, quantitative analysis and physical parameters of finished product are in compliance with the standard mentioned in GMP guidelines and requirements simultaneously supporting the impression of the polyherbal lozenges which can compete with the standard lozenges available in market.

The polyherbal lozenges were developed by thorough study of herbs, followed by optimization of formulation dosage and evaluation of qualitative and quantitative analysis by precised advanced analytical instrumental methods for assessment. The effectiveness has been analyzed by a survey through questionnaire. The study carried out has endorsed the quality and effectiveness of the polyherbal lozenges. This study reveals that the lozenges are suitable dosage form for the symptomatic relief of cold and flu. The standardization which provides a specific and rapid tool for setting the quality standard, identity and reproducibility in herbal lozenges for cold and flu. Hence the lozenges pass all the parameters and was found to be more effective in the treatment of cold and flu (As per the survey on 100 patients). Hence this formulation can be recommended for patients having cold and flu symptoms.

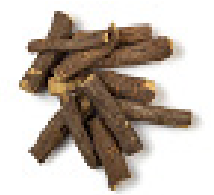

Liquorice

Long pepper

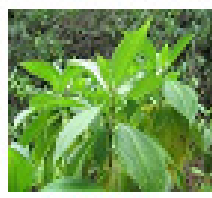

Vasaka

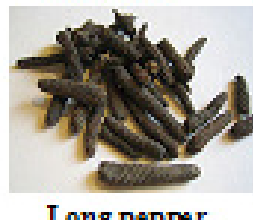

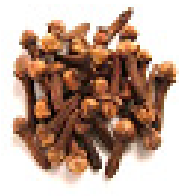

Clove

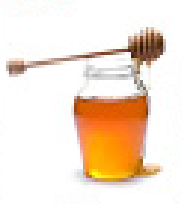

Honey

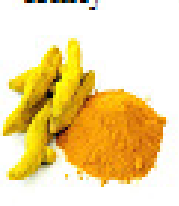

Termeric

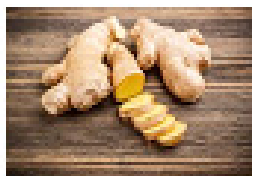

Ginger

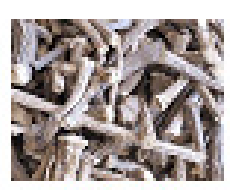

Guduchi
Figure 1: Harbal Ingredients used for Lazenges.

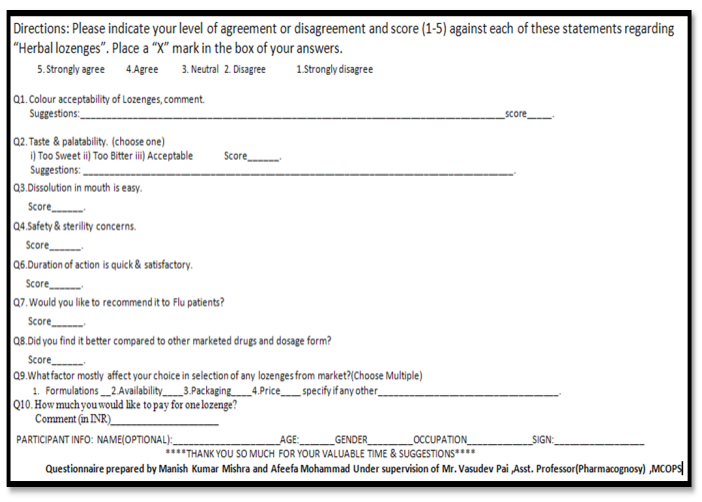

Figure 2: Questionnaire Pattern for Polyherbal Lozenges.

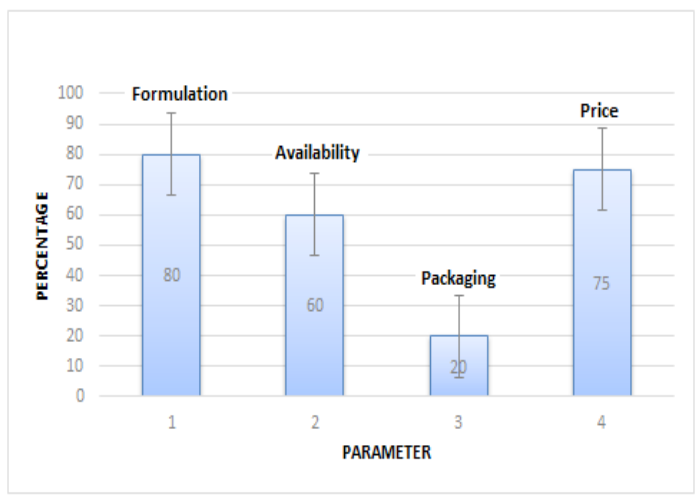

Figure 3: Acceptance Parameter Scoring.

\section{ACKNOWLEDGEMENT}

The authors are thankful to Manipal College of Pharmaceutical Sciences, MAHE, Manipal, India, for carrying out this work and providing sophisticated instruments facilities. 


\section{CONFLICT OF INTEREST}

The authors declare no conflict of interest.

\section{ABBREVIATIONS}

GMP: Good manufacturing practice.

\section{REFERENCES}

1. Panati C. Panati's extraordinary origins of everyday things. New York: Harper and Row. ISBN 0060964197. 1989;258 and 8211;260.

2. Aulton ME. Pharmaceutics: the science of dosage form design. Churchill Livingstone. 2000.

3. Prashar D, Saklani S. Formulation and evaluation of anthelmintic chewable tablets. IPS. 2012;2(1):13-6.

4. Birader. Formulation and evaluation of chewable tablets. Int J Pharmacy and Pharm Sci. 2006;2(6):461-4.
5. Bhowmik D, Pankaj C, Tripathi KK, Chandira MR, Kumar KPS. Zingiber officinale the herbal and traditional medicine and its therapeutically importance. Res J Pharmacognos Phytochem. 2010;2(2):102-10.

6. 6. Esimone $\mathrm{CO}$, Onuh $\mathrm{PU}$, Egege $\mathrm{MK}$, Ugoeze $\mathrm{KC}$, Obitte NC. In vitro evaluation of lozenges containing extracts of roots of Zapoteca portoricensis (FAM: Fabaceae). J Pharmacol Toxicol. 2009;4(3):132-7.

7. 7. Reading SJ, Spring MS. The effects of binder film characteristics on granule and tablet prop-erties. J Pharm Pharmacol. 1984;36(7):421-6.

8. 8. Kathiresan K, Vijin P, Moorthi C, Manavalan R. (2010) Formulation and evaluation of loratadine chewable tablets. Res J Pharm Biological Chem Sci. 2010; 1(4): 763-774.

9. 9. Abdelbary G, Eouani C, Prinderre P, Joachim J, Reynier JP, et al. (2004) Determination of the in vitro disintegration profile of rapidly disintegrating tablets and correlation with oral disinte-gration. Int J Pharm. 2004; 292(1-2): 29-41.

10. Bajelan E, Kamali-nejad M, Albasha H. Formulation and physicochemical evaluation of lozenge tablets containing Salvia officinalis. Journal of Young Pharmacists. 2014;6(1):34.

11. 10. Bajelan E, Kamali-nejad M, Albasha H. Formulation and physicochemical evaluation of loz-enge tablets containing Salvia officinalis. Journal of Young Pharmacists. 2014 Jan 1;6(1):34.

\section{PICTORIAL ABSTRACT}

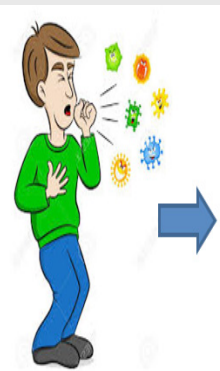

Cold and Flu

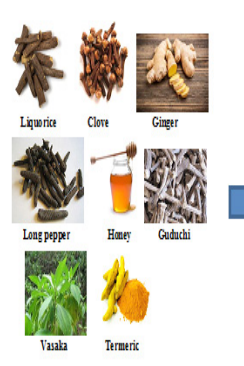

Herbal Ingredients

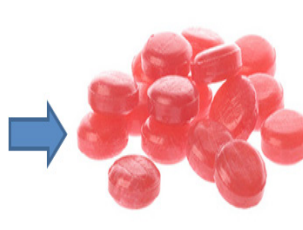

Lozenges

\section{ABOUT AUTHORS}
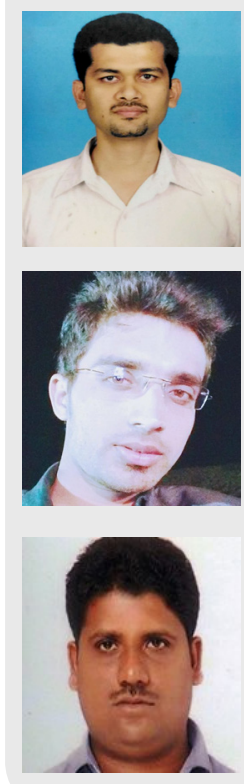

Mr. Vasudev Pai is an Assistant professor, Department of Pharmacognosy Manipal College of Pharmaceutical Sciences MAHE, Manipal.

Mr. Manish Kumar Mishra: is a Student, Department of Pharmacognosy Manipal College of Pharmaceutical Sciences MAHE, Manipal.

Dr. Chandrashekar KS is an Associate Professor, Department of Pharmacognosy Manipal College of Pharmaceutical Sciences MAHE, Manipal.

\section{SUMMARY}

- Lozenges are used to treat the symptoms like sore throat and congestion of throat which are the common in cold and flu. The developed lozenges includes many herbs having effect on respiratory tract and completely natural. The lozenges are evaluated for its quality and therapeutic efficacy by various parameters and feed-back of people having symptoms of cold and flu. The developed formulations comply with all the standards mentioned in GMP and can be used safely without any side effects.

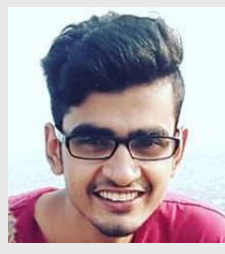

Mr. Anshul Kumar is a Student, Department of Pharmacognosy Manipal College of Pharmaceutical Sciences MAHE, Manipal.

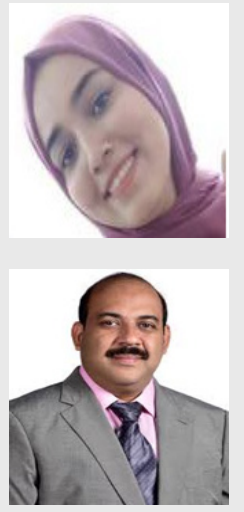

Ms. Afeefa is a Student, Department of Pharmacognosy, Manipal College of Pharmaceutical Sciences MAHE, Manipal.

Dr. Girish Pai is an Associate Professor, Department of Pharmaceutics Manipal College of Pharmaceutical Sciences MAHE, Manipal.

Cite this article: Kumar A, Mishra MK, Afeefa, Chandrashekar KS, Pai G, Pai V. Development and Evaluation of Polyherbal Lozenges for Cold and Flu. Indian J of Pharmaceutical Education and Research. 2019;53(2S):s159-s163. 